\title{
EXPOSIÇÃO OCUPACIONAL COM MATERIAL POTENCIALMENTE CONTAMINADO ENTRE PROFISSIONAIS DAÁREA DE APOIO
}

\author{
Natasha de Oliveira Morais ${ }^{1}$, Anamaria Melo Miranda Paniago ${ }^{2}$, Adriana Carla Negri ${ }^{3}$, Olcinei Alves de Oliveira ${ }^{4}$, \\ Rivaldo Venâncio da Cunha ${ }^{5}$, Sandra Maria do Valle Leone de Oliveira ${ }^{6}$
}

\begin{abstract}
RESUMO: Pesquisa descritiva, quantitativa, que se propôs a levantar a frequência de acidentes ocupacionais, envolvendo materiais biológicos potencialmente contaminados, que ocorreram entre os profissionais que atuam em um hospital de ensino e caracterizar aqueles que acometeram a equipe de higienização e limpeza e lavanderia. Foram analisadas 238 fichas de investigações de acidentes de trabalho do Serviço de Epidemiologia do período de 2004 a 2009. Destas, 10,9\% (26/239) correspondiam a acidentes ocorridos com profissionais da limpeza hospitalar, 2,5\% de profissionais da lavanderia. Foi predominante o sexo feminino, faixa etária de 30-40 anos, do tipo percutâneo, destacando-se os quirodáctilos como a área corporal mais atingida e o líquido potencialmente contaminado foi o sangue. Três grandes pilares de assistência devem ser fortalecidos: o sistema de informação para subsidiar a política institucional, a formação continuada dos profissionais que geram resíduos perfurantes e a aquisição de materiais com dispositivos de segurança.
\end{abstract}

PALAVRAS-CHAVE: Exposição ocupacional; Patógenos transmitidos pelo sangue; Serviços hospitalares de apoio.

\section{OCCUPACIONALEXPOSURE WITH POTENTIALLY HAZARDOUS BIOLOGICAL MATERIAL AMONG WORKERS IN HOSPITAL SERVICES}

\begin{abstract}
This is a descriptive and quantitative research which aimed to study the annual frequency of workplace accidents that occurred among health professionals and to characterize the occurrence of work acidentes involving hospital hygiene staff. 238 professional accidents' reports were analyzed, from the Epidemiology Department in an University Hospital, from 2004-2009. From the total, 10,9\% (26/238) corresponded to accidents with hygiene staff , and 2,5\% with the ones who worked at the laundry service. Data were gathered from the form of Surveillance System PSBio. It was observed that there was a greater frequency of accidents, especially among the female workers, aged from 30-40 years, with predominance of percutaneous exposure, especially the fingers as the most affected part of the body. Three pillars of assistance should be strengthened: the information system to support the institutional policy, continuing education of professionals who generate perforating residues and purchase of materials with safety devices.
\end{abstract}

KEYWORDS: Occupational exposure; Blood-Borne pathogens; Hospital services.

\section{EXPOSICIÓN OCUPACIONAL CON MATERIAL POTENCIALMENTE CONTAMINADO ENTRE PROFESIONALES DEL ÁREA DE APOYO}

RESUMEN: Investigación descriptiva, cuantitativa, que se propuso a levantar la frecuencia de accidentes ocupacionales, envolviendo materiales biológicos potencialmente contaminados, que ocurrieron entre los profesionales que actúan en un hospital de enseñanza y caracterizar aquellos acometieron el equipo de higienización y limpieza y lavandería. Fueron analizados 238 informes de expedientes de accidentes de trabajo del Servicio de Epidemiología entre 2004-2009. De estos, $10.9 \%$ (26/239) correspondían a accidentes ocurridos con profesionales de la limpieza hospitalaria, 2.5\% de profesionales de la lavandería. Fue predominante el sexo femenino, faja etaria de 30-40 años, del tipo percutáneo, destacándose los quirodáctilos como área corporal más afectada y el líquido potencialmente contaminado fue la sangre. Tres grandes pilares de ayuda deben ser fortalecidos: el sistema de información para subsidiar la política institucional, la formación continuada de los profesionales que generan residuos perforadores y la compra de materiales con dispositivos de seguridad.

PALABRAS CLAVE: Exposición ocupacional; Patógenos transmitidos por la sangre; Servicios hospitalarios de apoyo.

\footnotetext{
${ }^{1}$ Enfermeira.

${ }^{2}$ Médica Infectologista. Professora adjunto do Departamento de Clínica Médica da Universidade Federal do Mato Grosso do Sul-UFMS. ${ }^{3}$ Enfermeira do Trabalho. Membro do Serviço Hospitalar de Epidemiologia da UFMS.

${ }^{4}$ Enfermeiro. Docente do Departamento de Enfermagem da UFMS.

${ }^{5}$ Médico Infectologista. Professor assistente da Faculdade de Medicina Hélio Mandeta-UFMS.

${ }^{6}$ Enfermeira. Docente da Universidade Anhanguera-UNIDERP. Serviço Hospitalar de Epidemiologia da UFMS.
}

Autor correspondente:

Natasha de Oliveira Morais

R. Alagoas, 1778 - 79022-370 - Campo Grande-MS, Brasil

Recebido: 04/02/09

E-mail: natymorais@hotmail.com

Aprovado: 03/11/09 


\section{INTRODUÇÃO}

Cerca de um terço dos acidentes que ocorre em hospitais são produzidos por material pérfuro-cortante com material biológico potencialmente contaminado. Uma parte destes ocorrem com os trabalhadores dos serviços de apoio no decorrer de seu processo de trabalho de coleta de lixo hospitalar, e em atividades administrativas, quando tais materiais são descartados em local inadequado, como no chão, lixo comum ou em recipientes erroneamente adaptados ${ }^{(1-2)}$.

O processo de trabalho hospitalar exige interação entre diversos elementos humanos, recursos materiais e tecnológicos, o que torna a sua organização do processo de trabalho dinâmica, interdependente e complexa ${ }^{(3-4)}$. A exposição ocupacional a materiais biológicos, potencialmente contaminados, é um grave risco aos profissionais em seu local de trabalho. Os ferimentos com agulhas e material pérfuro-cortante, em geral, são considerados extremamente perigosos por serem capazes de transmitir 60 diferentes agentes infecciosos através de exposição a sangue e outros materiais biológicos, sendo o vírus da imunodeficiência humana, o da hepatite B e o da hepatite $\mathrm{C}$ os agentes infecciosos mais comumente adquiridos ${ }^{(4-6)}$. $\mathrm{O}$ risco de acidentes ocupacionais depende não somente do tipo de atividade, mas também da natureza do material manuseado e dos meios de proteção empregados ${ }^{(2)}$.

Contudo, além dos profissionais de saúde, outras categorias de profissionais, mesmo não envolvidas no cuidado direto aos pacientes, têm sido vítimas de acidentes de trabalho com materiais perfurocortantes potencialmente contaminados com fluidos orgânicos ${ }^{(7-8)}$.

Os acidentes que ocorrem com os profissionais de apoio - higienização e limpeza e lavanderia merecem atenção, pois envolvem risco de infecção por patógenos sanguíneos e possuem como agravante o fato de que, em muitas situações, não há a possibilidade de identificação do paciente fonte ${ }^{(8-9)}$.

Estudos dessa natureza devem servir como fonte de informações para administradores subsidiarem a adoção de medidas educativas e desenvolverem estratégias preventivas, especialmente, entre os trabalhadores de higienização e limpeza ${ }^{(7-9)}$.

O objetivo desse estudo foi analisar a frequência de acidentes ocupacionais envolvendo materiais biológicos potencialmente contaminados que ocorreram entre os profissionais que atuam em um hospital de ensino e caracterizar aqueles que acometeram a equipe de higienização, limpeza e lavanderia.

\section{METODOLOGIA}

Trata-se de pesquisa descritiva de abordagem quantitativa, realizada no Serviço Hospitalar de Epidemiologia de um hospital público de ensino da capital do Mato Grosso do Sul, na qual foi levantada a frequência e as características dos acidentes de trabalho com exposição a material biológico investigados no período de 2004 a 2009.

A coleta de dados foi realizada nas fichas de investigação epidemiológica de notificação e investigação de casos: ficha do Projeto Risco Biológico-PSBio, do Sistema de Informação de Agravos de Notificação Compulsória-SINAN e nos prontuário dos indivíduos atendidos no serviço de referência, neste caso, os profissionais que sofreram acidente de trabalho.

O projeto foi aprovado pelo Comitê de Ética da Universidade Federal de Mato Grosso do Sul-UFMS sob protocolo 877 e todos os participantes assinaram, no momento do atendimento e da notificação, o Termo de Consentimento Livre e Esclarecido atendendo à Resolução n. 196/96 do Conselho Nacional de Ética em Pesquisa do Conselho Nacional de Saúde.

\section{RESULTADOS}

De 2004 a 2009 foram registrados 238 acidentes entre todos os profissionais da instituição, conforme Tabela 1. Destacam-se os profissionais de enfermagem com 40,6 \% e da área médica 24,3 \%. A exposição percutânea ocorreu em 79,8 \% (190/238), por recapeamento de agulhas, $78,1 \%(178 / 228)$ e envolveram sangue 12,9\% (27/209). Destes, 12,4\% (30/ 238) eram profissionais do grupo de apoio: higienização e limpeza e lavanderia, terceiro grupo mais registrado.

Tabela 1 - Frequência e caracterização dos acidentes envolvendo material potencialmente contaminado entre trabalhadores de saúde. Campo Grande-MS, 2004-2009. $(\mathrm{N}=238)$

\begin{tabular}{lcc}
\hline Categoria profissional & \multicolumn{2}{c}{ Variáveis } \\
\hline & $\mathrm{N}^{\mathrm{o}}$ & $\%$ \\
\hline Equipe de enfermagem & 98 & 40,6 \\
Equipe médica & 59 & 24,6 \\
Setor de higienização e limpeza & 26 & 10,7 \\
Equipe de odontologia & 22 & 9,1 \\
Equipe de laboratório & 19 & 8,0 \\
Setor de lavanderia & 4 & 1,7 \\
\hline
\end{tabular}


Continuação

\begin{tabular}{lcc}
\hline Categoria profissional & \multicolumn{2}{c}{ Variáveis } \\
\hline & $\mathrm{N}^{\mathbf{0}}$ & $\%$ \\
\hline Serviço administrativo/transporte & 2 & 0,8 \\
Fisioterapeuta & 1 & 0,4 \\
Outras & 8 & 3,3 \\
Tipo de exposição & & \\
Percutânea & 172 & 72,2 \\
Mucosa & 29 & 12,1 \\
Percutâneo/mucocutâneo & 18 & 7,5 \\
Cutânea & 11 & 4,6 \\
Mucocutânea & 2 & 0,8 \\
Não informado & 6 & 2,5 \\
Tempo de atuação & & \\
$<1$ ano & 28 & 17,2 \\
1 a 5 anos & 69 & 42,3 \\
5 a 10 anos & 28 & 17,2 \\
10 a 20 anos & 25 & 15,3 \\
$>$ 20 anos & 13 & 8,0 \\
& &
\end{tabular}

Local de ocorrência do acidente

\begin{tabular}{lcc} 
Ambulatório & 23 & 10 \\
Banco de sangue & 8 & 3,5 \\
Centro cirúrgico & 31 & 13,6 \\
Enfermaria clínica & 41 & 18,1 \\
Enfermaria cirúrgica & 12 & 5,3 \\
Enfermaria obstétrica e sala de parto & 8 & 3,1 \\
Hospital - Dia de doenças infecciosas & 3 & 1,3 \\
Laboratório & 16 & 7,0 \\
Serviço de emergência & 27 & 11,8 \\
Setor de lavanderia & 5 & 2,2 \\
Unidade de terapia intensiva & 21 & 9,2 \\
Unidade de diálise & 5 & 2,2 \\
Outros (Necropsia, Radiologia) & 23 & 12,6 \\
Área corporal atingida & & \\
Dedos das mãos & 169 & 69,0 \\
Membros superiores (exceto dedos) & 19 & 7,8 \\
Tronco ou abdome & 2 & 0,8 \\
Membros inferiores & 11 & 4,5 \\
Olhos & 28 & 11,4 \\
Boca, nariz, face (sem contato com & 16 & 6,5 \\
mucosa), outra área corporal & & \\
\hline
\end{tabular}

Nota: os dados excluem a informação ignorado em todas as variáveis assinaladas, pois o $\mathrm{N}$ é diferente nas diversas tabelas em função da frequência de preenchimento da variável em questão.

Tabela 2 - Características dos acidentes ocorridos entre profissionais da higienização e limpeza e lavanderia entre profissionais do grupo de apoio. Campo Grande-MS, 2004$2009(\mathrm{~N}=30)$

\begin{tabular}{lcc}
\hline Características das exposições biológicas & \multicolumn{2}{c}{ Variáveis } \\
\hline & $N^{\circ}$ & $\%$ \\
\hline
\end{tabular}

Tipo de exposição

Percutânea

2893,4

Pele

13,3

Não informado

13,3

Local de ocorrência do acidente

$\begin{array}{lll}\text { Enfermaria de clínica } & 9 & 30,0\end{array}$

Lavanderia

$4 \quad 13,3$

Centro cirúrgico

310,0

Serviço de emergência

310,0

Laboratório

26,7

Unidade de diálise

26,7

Enfermaria de cirúrgica

13,3

Fora do hospital

13,3

Outros locais (serviço de radiologia, medicina Nuclear)

Área corporal atingida

Dedos das mãos

$17 \quad 56,7$

Membros inferiores

$7 \quad 23,3$

Membros superiores (exceto dedos)

310,0

Boca, nariz, face sem contato com mucosas, outra área corporal

310,0

Tipo de material

Agulha hipodérmica

1860,0

Agulha com lumen

310,0

Vidro/estilete de cateter IV/lâmina de bisturi $\quad 5 \quad$ 16,7

Desconhecido, mas perfurante

$4 \quad 13,3$

Localização do material causador do acidente

Saco de lixo

930,0

Material no chão

$8 \quad 26,7$

Material em local impróprio (janela,

bancada, mesa de cabeceira, hamper)

$5 \quad 16,7$

Manuseio de roupa suja na lavanderia

$4 \quad 13,3$

Trânsito para descarte

13,3

Limpeza de material cirúrgico

26,7

Outros 
Dos profissionais da área de apoio, que se acidentaram, 86,7\% (26/30) eram do sexo feminino, com faixa etária de 30 a 50 anos, 66,7\% (20/30). O tempo de atuação predominante era de 1 a 5 anos (17/30). As características dos acidentes ocorridos entre profissionais da higienização e limpeza e lavanderia estão contidas na Tabela 2.

\section{DISCUSSÃO}

Do universo de acidentes, envolvendo a enfermagem e o grupo médico, predominaram os acidentes entre a equipe de enfermagem, o que é corroborado em resultados similares nos quais foram encontrado de $40-58 \%$ de acidentes registrados nestas categorias profissionais ${ }^{(7-8,11)}$.

Dos trabalhadores do serviço de higienização e limpeza hospitalar e lavanderia, 12,7\% (30/238) registraram acidentes envolvendo material biológico. Estudos em hospitais terciários encontraram prevalência de 3,3-5,2 \% entre profissionais de limpeza ${ }^{(8-11)}$.

Observou-se o predomínio de acidentes com os trabalhadores do sexo feminino e com faixa etária de 31 a 40 anos (8/17), porém mesmo constatando que a força de trabalho é predominantemente feminina nas unidades hospitalares, alguns estudos apontam que as mulheres parecem acidentar-se duas vezes mais do que os homens, fato que deve ser melhor investigado. A predominância no grupo feminino pode ter uma relação histórica, pois o cuidado com o ambiente em hospitais é realizado basicamente por mulheres ${ }^{(7-9)}$.

Os acidentes, na população estudada, foram predominante percutâneo, com maior frequência de agulhas hipodérmicas em quirodáctilos, com moderada profundidade, com material biológico desconhecido. Alguns estudos encontraram perfil semelhante entre trabalhadores da higienização e limpeza ${ }^{(8-10)}$.

Atenta-se que esse perfil epidemiológico tem as mesmas peculiaridades dos acidentes que ocorrem em profissionais de outras categorias, apesar da atividade de apoio se tratar de uma atividade meio e, portanto, não envolver atividades assistenciais diretas com o paciente. Cabe reforçar que em acidentes com pérfuro- cortantes cuja fonte seja desconhecida, em geral não se recomenda a quimioprofilaxia ${ }^{(5,8,11)}$.

A frequência das atividades assistenciais que requererem a utilização de dispositivos pérfuro-cortantes, a dinâmica e o ritmo acelerado imposto em serviços de saúde, especialmente em locais como os serviços de urgência e clínica médica aumentam o risco de acidentes com material biológico. Essas características do processo e organização da atividade laboral desenvolvido por profissionais da área de enfermagem e médica dificultam a prevenção desses acidentes, as quais são ocasionadas por resíduos causadores de exposições ocupacionais no pessoal de apoio ${ }^{(8)}$.

A localização mais frequente dos perfurocortantes que ocasionaram acidentes foram os sacos de lixo (9/ 30), seguido de material encontrado no chão (8/30). Tais acidentes com o pessoal de apoio, higienização e limpeza e lavanderia, ocorrem com materiais descartados em locais inadequados, como em lixo comum, leitos ou mesas de cabeceira, ou em recipientes erroneamente adaptadas, perfurando, em especial, as mãos, durante a limpeza do chão ou áreas assistenciais. Os profissionais de saúde favorecem que estes acidentes ocorram quando descartam agulhas e materiais cortantes/perfurantes em locais impróprios Acidentes associados podem chegar até 55\% em locais devido a descarte inadequado de resíduos de saúde ${ }^{(10-11)}$.

A baixa instrução e o treinamento insuficiente tornam este grupo vulnerável ao risco de adoecimento associado a exposição ocupacional ${ }^{(10)}$. A valorização dos procedimentos de limpeza e a formação do pessoal implica diretamente em um melhor ambiente de trabalho, menor taxa de infecção hospitalar. Acreditase que este é caminho a ser percorrido em busca da qualidade na área da saúde $\mathrm{e}^{(5,10-11)}$.

\section{CONSIDERAÇÕES FINAIS}

Este estudo permitiu levantar a frequência de acidentes ocupacionais, envolvendo materiais biológicos potencialmente contaminados, que ocorreram entre os profissionais que atuam em um hospital de ensino e caracterizar aqueles que acometeram a equipe de higienização e limpeza e lavanderia.

Para o fortalecimento de práticas integradas capazes de proporcionar segurança e ambiente saudável, três pilares de assistência devem ser fortalecidos: o sistema de informação para subsidiar a política institucional, a formação continuada dos profissionais que geram resíduos perfurantes ocasionando acidente nos profissionais da limpeza e a inserção de tecnologias seguras como dispositivos de segurança, que se não eliminariam poderiam reduzir drasticamente acidentes perfurocortantes nesta população.

\section{REFERÊNCIAS}

1. Santana VS, Araújo-Filho JB, Albuquerque-Oliveira PR, Barbosa-Branco A. Occupational accidents: social 
insurance costs and work days lost. Rev Saúde Publ. 2006 Dec;40(6):1004-12.

2. Silva CER. O processo de trabalho da limpeza e coleta interna do lixo hospitalar na emergência do hospital municipal Paulino Werneck [dissertação] Rio de Janeiro (RJ): Centro de Estudos de Saúde do Trabalhador e Ecologia Humana, Escola Nacional de Saúde Pública; 1999

3. Osório C, Machado JMH, Minayo-Gomez C. Proposal of a method for collective analysis of work-related accidents in the hospital setting. Cad Saúde Publ. 2005 Apr;21(2):517-24.

4. Acosta, JMA. Avaliação do sistema de gestão de riscos de acidentes com instrumentos pérfuro-cortantes na atividade de limpeza de hospitais públicos através da analise ergonômica do trabalho [dissertação]. Belo Horizonte (MG): Escola de Engenharia, Universidade Federal de Minas Gerais; 2004.

5 Ministério da Sáude (BR). Exposição a materiais biológicos. Protocolos de Complexidade Diferenciada 3. Série a. Normas e Manuais Técnicos. 2006.

6. Tarantolaad A, Abiteboulbd D, Rachlinecd A. Infection risks following accidental exposure to blood or body fluidsin health care workers: A review of pathogens transmitted in published cases. AJIC. 2006; 34: 367-75

7 Paulino DCR; Lopes MVO, Rolim ILTP. Biossegurança e acidentes de trabalho com pérfuro-cortantes entre os profissionais de enfermagem em um hospital universitário de Fortaleza-CE. Cogitare Enferm. 2008 Out/Dez;13(4):507-13.

8. Oliveira BAC, Kluthcovsky ACGC, Kluthcovsky FA. Estudo sobre a ocorrência de acidentes de trabalho com material biológico em profissionais de enfermagem de um hospital. Cogitare Enferm. 2008 Jan/Mar;13(2):194205.

9. Canini SRMS, Gir E, Machado AA. Accidentes with protentially hazardours biological material among workeres in hospital supporting services. Rev LatinoAm Enferm. 2006 Jul/Ago;13(4):496-500

10. Erdem Y, Talas MS. Blunt and penetrating objects injuries in housekeepers working in a Turkish university hospital. AJIC. 2004 May;34(6):208-13.

11. Balsamo AC, Felli VE . Study of work accidents related to human body fluids exposure among health workers at a university hospital. Rev Latino-Am Enferm. 2006 Jun;14(3):346-53. 